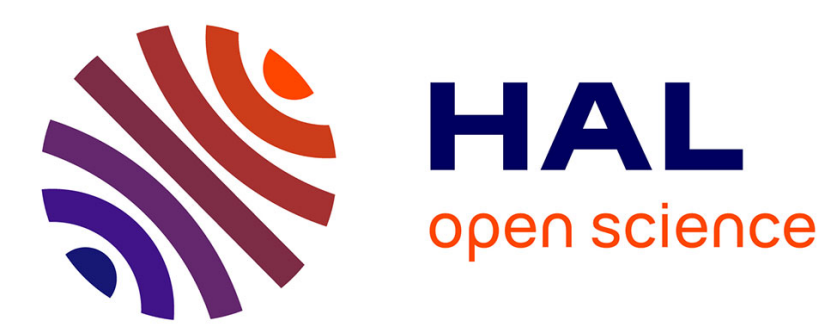

\title{
An Unmanned Aerial Vehicle-based System for Large Scale Metrology Applications
}

Fiorenzo Franceschini, Luca Mastrogiacomo, Barbara Pralio

\section{To cite this version:}

Fiorenzo Franceschini, Luca Mastrogiacomo, Barbara Pralio. An Unmanned Aerial Vehicle-based System for Large Scale Metrology Applications. International Journal of Production Research, 2010, 48 (13), pp.3867-3888. 10.1080/00207540902896220 . hal-00593341

\section{HAL Id: hal-00593341 https://hal.science/hal-00593341}

Submitted on 14 May 2011

HAL is a multi-disciplinary open access archive for the deposit and dissemination of scientific research documents, whether they are published or not. The documents may come from teaching and research institutions in France or abroad, or from public or private research centers.
L'archive ouverte pluridisciplinaire HAL, est destinée au dépôt et à la diffusion de documents scientifiques de niveau recherche, publiés ou non, émanant des établissements d'enseignement et de recherche français ou étrangers, des laboratoires publics ou privés. 


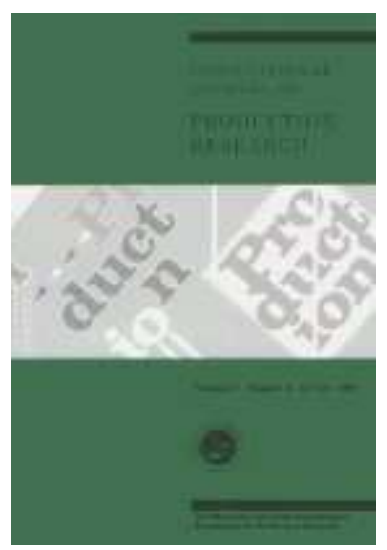

\section{An Unmanned Aerial Vehicle-based System for Large Scale Metrology Applications}

\begin{tabular}{|c|c|}
\hline Journal: & International Journal of Production Research \\
\hline Manuscript ID: & TPRS-2009-IJPR-0158.R1 \\
\hline Manuscript Type: & Original Manuscript \\
\hline $\begin{array}{r}\text { Date Submitted by the } \\
\text { Author: }\end{array}$ & 10-Mar-2009 \\
\hline Complete List of Authors: & $\begin{array}{l}\text { Franceschini, Fiorenzo; Politecnico di Torino, Dip.to Sistemi di Prod } \\
\text { ed Econ dell'Azienda } \\
\text { Mastrogiacomo, Luca; Politecnico di Torino, DISPEA } \\
\text { Pralio, Barbara; Politecnico di Torino, DISPEA }\end{array}$ \\
\hline Keywords: & METROLOGY, QUALITY CONTROL, PRODUCT DESIGN, SENSORS \\
\hline Keywords (user): & $\begin{array}{l}\text { large scale metrology, wireless sensor networks, autonomous } \\
\text { unmanned vehicles }\end{array}$ \\
\hline
\end{tabular}

\section{今 ScholarONE \\ Manuscript Central}




\section{An Unmanned Aerial Vehicle-based System for Large Scale Metrology Applications}

Fiorenzo Franceschini, Luca Mastrogiacomo, Barbara Pralio

POLITECNICO di TORINO

Dipartimento di Sistemi di Produzione ed Economia dell'Azienda

Corso Duca degli Abruzzi 24, 10129 - Torino, ITALY

Tel. +39011 5647225, Fax. +39 011 5647299, e-mail: fiorenzo.franceschini@polito.it

\section{Abstract}

Different manufacturing environments, such as aerospace, automotive, shipbuilding, and railway, reveal their interest in Large Scale Metrology (LSM) instruments, to provide a support in assembly, alignment, inspection, and robot tracking tasks.

Notwithstanding different levels of portability, the overall measurement procedure actually involves a direct interaction between the measuring equipment and the operator, as well as a strong dependence on human skills.

This paper presents a novel metrological system, scaling down this interaction to a mission management task and aimed at uniforming system performance. The proposed architecture entrusts an unmanned aerial vehicle (UAV) with the task of carrying the sensor equipment and of moving the measuring probe.

The design process of the proposed system is detailed and faced with a two-level approach. The first level is directed to identify the available start-up technology, its limitations and sensitivity to the design parameters, while the second level is focused on the experimental testing of a preliminary test-bed to investigate the overall system performance. An actual implementation of the proposed architecture is herein discussed, focusing on system feasibility and presenting some preliminary experimental results.

Keywords: large scale metrology, autonomous unmanned vehicles, wireless sensor networks, cooperative control. 


\section{Introduction}

Large scale metrology (LSM) is a challenging application, involving many areas of engineering, such as aerospace, shipbuilding and fundamental science research. Different metrological systems for measuring large-sized objects within factory facilities are industrially available, mainly consisting of photogrammetry equipment, laser tracker and the more recent indoor GPS system. These systems are based on optical technologies and they are characterized by a common architecture, generally consisting of three main modules: the measuring hardware, the sensor carriage and the ground control station. Performance of these systems can be measured in terms of portability, installation and start-up complexity, cost, metrological accuracy, working volume, easiness-of-use, and flexibility. Despite different technological hardware, all metrology solutions encompass the capability to perform measurements by hand-held probes, in an attempt to remove limitations associated to articulated arms. On the other hand, metrological performances are usually affected by user's experience and skills. In order to overcome limitations and to improve measuring procedures, a novel approach to large-medium sized object measurement should result in technologies being free from human external influence. Primary consequences of the proposed approach are expected to be a reduction in inspection and manufacturing time due to the automation of the measuring task and a better reproducibility of measurements.

The wide variety of applications involving sensor mobility issues, from environmental monitoring to dimensional measurements, is responsible for the growing interest in innovative sensor-carrying platform solutions. In recent years several research activities have been focused on the integration of autonomous unmanned vehicles in different operating environments, from ground to air and water. Proper indicators of system effectiveness cannot be uniquely defined within the broad field of different applications and mission tasks. However, capability to identify a system requirement set for a category of applications should be profitably investigated to define a standard of evaluation.

This paper presents an alternative solution to conventional architectures of metrological systems, based on the automation of the sensor carrying and measurement acquisition tasks. Furthermore, the research work aims to provide an outline of standard requirements for evaluating feasibility of new solutions for large scale metrology. Section 3 provides an overview of system architectures currently available for LMS applications, highlighting advantages and drawbacks. Autonomous unmanned vehicles are, then, subject of a background subsection, focusing on innovation associated to their use. Section 4 outlines the 


\section{Background}

\subsection{System architectures for large scale metrology applications}

Different manufacturing environments reveal their interest in 3D technologies able to provide a support in assembly, alignment, metrology, inspection, and robot tracking tasks. Applications involve part/subpart verification and validation, quality control as well as reverse engineering.

The Coordinate Measuring Machine (CMM) is still the most widespread technology for industrial dimensional metrology. Even if classical and gantry CMMs are widely used in some industrial environments, often they result unsuitable for large scale metrology since they are expensive, bulky and difficult to move. For this reason the interest in alternative technological solutions is leading the research towards different directions:

- Optical technology characterizes tracking systems having unequaled accuracy, large working volumes, high flexibility and portability features. They encounter for system complexity, high costs and sensitivity to environmental interferences obstructing the optical path between transmitter and receiver (Newman et al., 2006, ANSI/ASME, 2006, Welch et al., 2001).

- Mechanical systems, based on potentiometers or optical encoders measuring joints' angular position, are characterized by simple design and manufacturing, high costs and reduced sensitivity to environmental interferences, but they have a small working volume and reduced degrees-of-freedom (Ohara, 2001). 
- Electromagnetic systems, although they are able to cover large working volumes by combining several devices, are strongly affected by electromagnetic interferences, that could be caused by metallic items being near the transmitting/receiving unit (Anderson et al., 2006).

- Inertial tracking systems, based on gyroscopic technology, are characterized by easiness-of-use and do not need any transmitting or receiving hardware. However, measurement accuracy is affected by drift and temperature sensitivity and strongly related to sensor recalibration (Newman et al., 2006, Chen et al., 1994).

- Acoustic technology could be implemented for metrology applications, by measuring the Time-of-Flight (ToF) or the Receiving-Signal-Strength (RSS) of a signal travelling from the transmitting unit to the receiving one. Contrary to optical-based systems, they involve cheap and market-available devices, but their accuracy is much lower and more sensitive to external interferences (Franceschini et al., 2008; Priyantha et al., 2000).

Although different technologies have been applied to equip metrological instruments, nowadays optical systems clearly demonstrates several advantages over all the other approaches. Several optical-based instruments compete for LSM applications, ranging from theodolites, total stations, jointed-arm CMMs and photogrammetry to the more recent laser trackers, laser radars and indoor GPS.

A taxonomy is herein proposed (Fig. 1), classifying LSM solutions within contact and non contact instruments. The former category consists of target-based systems, following reflective targets positioned against the object to be measured, and probe-based systems, tracking the position of measuring probes touching the object. The portability characteristics of probing systems and their degrees-of freedom provide the way for a further classification into wired and wireless systems. Existing solutions for large scale metrology, widely using armless wireless devices, are based on hand-held probes. The taxonomy emphasizes the present lack of alternative solutions to the hand-held probes for wireless probing systems.

\section{Insert Fig. 1}

Notwithstanding the differences highlighted by these classifications, a common architecture can be outlined. It consists of the measuring equipment, the communication network and the monitoring station (Fig. 2). 
The measuring equipment affects metrological performances and system flexibility. It generally consists of the sensors and the related housing. It gives rise to a classification based on working principles: optical-based systems use two angles and one length (laser tracker, laser radar, total stations), multiple angles (camera-based triangulation, indoor GPS, photogrammetry), or multiple lengths (multiple laser trackers) (Cuypers et al., 2008)

The communication task is shared between fixed station(s) and remote sensor set. The fixed station could be centralized, like laser trackers do, or it could be distributed among several units, at last constituting the nodes of a wireless sensor network, as indoor GPS and photogrammetry do. Complementary sensor set could be housed directly on the measured part, mainly for mating of large objects during assembling phases, or could be attached to portable probes for position and orientation measurements.

The measurement task monitoring is demanded to a control station, where data are elaborated and used for real-time geometry reconstruction. Advanced software packages are available to manage data obtained by different measurement approaches (manual, automatic, point-topoint, scanner) and to provide powerful tools for CAD programming and reverse engineering.

\subsection{Autonomous Unmanned Vehicles}

Interest in Autonomous Unmanned Vehicles (AUVs) has to be ascribed to the capability to perform repetitive and/or dangerous tasks without human intervention, preserving him/her from risks and waste of time (Schoenwald, 2000). Advances in control theory and automation technologies play a key role in AUVs' success, as capability to assess reliable control strategies has to be granted. Several application fields have been experimented for such vehicle category, involving different operating environments (ground, water, air and space), trying to evaluate their effectiveness with respect to existing solutions.

Among the autonomous vehicles, a growing interest has been registered in the last decade, for both military and civil applications, by government agencies, universities, research centers and industries, for unmanned aerial platforms (UAVs). UAVs are six Degrees-of-Freedom aerial robots, designed to perform dull, dirty and dangerous missions, reducing or even cancelling the risk for pilot and onboard crew by "putting them on ground". The peculiarity related to the transformation of the human role from onboard pilot to ground operator, represents, first of all, a philosophical innovation characterizing uninhabited aircraft (Wilson, 2002). This innovation implied designers, potential users and, finally, the whole society to trust in automatic flight management, onboard as well as ground-based hardware and software 
reliability. Nowadays, they represents a technological innovation in terms of system architecture, related to platform configuration, onboard systems, communication links and mission management. As a matter of fact, design effort is focused on the overall UAV system, intended as one (or more) aerial platform(s) and ground control unit(s) performing a mission profile, mutually exchanging information for optimizing the system effectiveness. Several classification criteria (Wood, 2002) have been applied to UAVs, mainly based on platform (i.e. configuration, dimension, weight), mission profile (i.e. range, operating altitude, flight duration), and remote control approach (i.e. remote piloting, semi-autonomous flight, autonomous flight). The primary rule commonly applied by designers is "to build the platform around the payload" and, therefore, to address, as key issue, the mission task.

\section{The basic idea}

A state-of-the-art analysis of existing probe-based portable coordinate measuring machines highlights the uniqueness of human-based solutions as sensor carrying platform (see Fig. 2). Transmitting task can be demanded to a single unit (centralized system), or to multiple units within the working environment (distributed system). According to this operating scheme, a wireless sensor-network-based system (MScMS - Mobile Spatial coordinate Measuring System) has been developed to perform indoor dimensional measurements of medium-large sized object (Franceschini et al., 2008). It consists of a network of ultrasound devices, an hand-held probe to touch the measurement points, and a processing system for evaluating geometrical features of the measured object.

\section{Insert Fig. 2}

Notwithstanding different levels of portability characterizing existing probe-based systems, the measurement procedure involves a "direct" physical interaction between the measuring technology and the ground operator. Novel metrological systems, scaling down this interaction to a mission management task, should be based on alternative solutions for sensor probe movement. Towards this direction is steered the basic idea of the present paper. It consists of an integrated system for large volume measurements, adequately responding to the need for six degrees-of-freedom, by providing an armless and wireless automated and autonomous solution. The novelty of the proposed system is related to the platform carrying the sensors, to the criteria for managing measuring technology and mission tasks, and to the platform modularity with respect to the technological hardware used for measurement. 
The novel approach herein proposed is tailored to the capability of carrying the sensor probe, achieving a satisfactory trade-off among metrology performance, system flexibility, and reducing the human intervention on the measuring task. An unmanned aerial vehicle is proposed to carry onboard the hardware and to perform the measurement, according to different level of self-government and task automation.

By entrusting to unmanned vehicles, implications related to practical and economic issues are expected. They are related to the following aspects:

- cutting of system setup costs, associated to the capability of performing a standard and automated setup procedure;

- reduction of inspection/manufacturing time, due to the capability of quickly transferring the sensor probe within the measurement volume;

- reduction of human intervention in the operating task, freeing measurement results from human skills dependence.

It should be noted that the "weight" of the abovementioned advantages is directly proportional to the level of automation introduced in the system and, hence, to the complexity of the system design and testing.

Different unmanned solutions could be taken for carrying the measuring hardware. A ground robot, representing an unmanned land vehicle, could be employed aimed to perform an automated reproduction of human actions. Although the automation of measurement actions should introduce uniformity of operating performances, reproducing human actions means no advantages in terms of inspection/manufacturing time and the same physical limitations. On the other hand, an aerial vehicle, due to its upgraded mobility features, could cover the same working volume easier and faster than a ground operator, even if autonomous.

On the other hand, the proposed system has two main drawbacks:

A. metrological performances are affected by platform dynamics (structural vibrations)

B. measurement of hidden/difficult to reach points is unfeasible.

While the former issue is strictly related to the airborne solution, the measurement of hidden points is a limitation shared with other existing metrological instruments.

The design process of such an integrated system faces with the following challenging issues:

1. the vehicle flight control is affected by several uncertainties, represented by structural vibrations, affecting dynamic stabilization, and by indoor positioning accuracy;

2. the automation of mission tasks should be based on a mission manager assigning the reference mission profile and should demand to the flight control system the overall mission accomplishment and, whether needed, the possible mission reconfiguration; 
3. platform-related performance, such as flight duration and mission range, are strongly affected by aircraft configuration design and are expected to limit overall system performance instead of those related to the measurement technology.

Furthermore, the proposed system introduces a novel conceptual approach to Large Scale Metrology operating procedures. Ground operator is responsible for monitoring the measurement session results and he/she does not play an active role in performing measurements. The mission profile, either a priori determined or real-time defined, is managed by a PC through the mission manager algorithms. The ground station is, therefore, responsible not just for gathering and elaborating measurement data, but it plays a key role in managing the mission tasks, controlling the aerial platform and verifying the status of airground-air communication.

\section{Requirements definition}

The reference application sets out the basic requirements for systems devoted to dimensional measuring. A comprehensive list of factors influencing the selection of a coordinate measuring machine has been given in (Cuypers et al., 2008), including task requirements (accuracy, reliability of results, location of points, ...), part restrictions (dimensions, material, accessibility, ...) and environmental restrictions (vibrations, temperature, available space, ...).

On the other hand, a state-of-the-art analysis of commercial and research unmanned platforms highlights different fields of application and mission profiles. Mission profiles, basically, concern remote sensing aimed to territorial monitoring and/or environmental mapping, within a wide variety of contexts (fire prevention, geological recognition, volcanic area surveillance, traffic monitoring, search and rescue aerial support, air pollution monitoring). Nevertheless, the application of unmanned systems to dimensional measurement of large sized objects appears to be an original and not yet explored sector.

As many solutions are available for large scale metrology, the proposed system should base its innovative characteristics on satisfying the following system-related requirements:

i. portability: it refers to the capability of the system to be moved and integrated in a working environment;

ii. flexibility: it has to be intended in terms of environmental adaptability and payload interchangeability for application in different contexts; 
iii. easiness-of-use: it is aimed to reduce the number of ground operators and their level of knowledge of the system;

iv. metrological performances: they are intended as level of metrological characteristics;

v. cost: it has to grant competitiveness with respect to the existing systems;

and platform-related requirements:

a. size: it has to be consistent with indoor applications;

b. mission profile: it has to include stationary positioning in order to keep on site measuring devices as long as required for sensor data acquisition and communication;

c. payload weight fraction: it has to be consistent with carrying on board the measuring technology, the sensor housing and the communication devices;

d. mission duration and range: they have to grant system effectiveness and adequate competitiveness with respect to existing coordinate measurement systems;

e. platform stabilization: it has to be adequately granted in order to perform accurate and repeatable measurements.

It has to be noted that the platform-related requirements play a key role within the configuration design phase. Table I outlines a preliminary numerical quantification of the above mentioned design requirements:

\section{Insert Table I}

The need for performing stationary flight mainly influences the designers to choose a rotary wing configuration or a lighter-than-air aircraft. On the other hand, a maximum dimension lower than $1 \div 1.5$ meters should grant to operate indoor correctly and safely, supporting, in the meanwhile, system portability. Platform size and weight are strongly related and they, intrinsically, come into conflict with payload weight and mission duration requirements. As a matter of fact, aerial platforms characterized by lower take-off weights have reduced payload weight fractions, affecting the capability to carry on board sensors, and reduced energy source weight fractions, corresponding to reduced flight duration. A trade-off analysis should result in the best solution achieving the platform requirements maximizing the overall system effectiveness. Although requirements related to mission profile and platform stabilization are difficult to be defined, they play a key role in system feasibility analysis and configuration definition. Platform stabilization is a critical issue as it is strongly related to the mission task 
(image acquisition needs different levels of platform stabilization with respect to environmental mapping or coordinate measurement) and a unique performance indicator is hard to be defined. Concerning dimensional measuring applications, stabilization can be intended as capability to grant a steady contact (either physical or visual) between the measuring hardware and the measured object, reducing platform movement due to trim variations as well as structural vibrations. Proper system characterization should be carried out by experimental testing to estimate the influence of platform dynamics on metrological performances.

\section{System architecture}

The architecture of the proposed system, integrating UAV platforms with wireless sensor networks, consists of the following modules (Fig. 3):

A) Integrated Aerial Measuring System (IAMS): it consists of the aerial platform equipped with onboard hardware for communicating with the ground station, implementing platform stabilization and control, and performing measurement data processing and elaboration;

B) Integrated Airborne Probe (IAP): it includes the mobile probe for physically touching the measured object, the wireless device(s), communicating with the reference local positioning system and performing distance measurements, and the related housing needed to integrate it with the IAMS;

C) Ground Control Station (GCS): it consists of hardware devices (PC laptop/palmtop, virtual reality equipment) for managing the ground-air-ground communication and for processing and/or storing measurement and flight-related data.

\section{Insert Fig. 3}

As the aircraft design is a complex, iterative and time-spending process, a cost-effective project should plan to adapt an aerial platform selected among the available commercial offthe-shelf products. The research can then be focused on developing an integrated system able to fully match the mission requirements and the competitive capabilities (metrological performance, flexibility, modularity) with respect to the existing coordinate measuring systems, either mobile or not. 
The measuring technology implementation sets the design rules of the Integrated Airborne Probe, as it influences the hardware for physical connection to the IAMS and the need for appropriate on board location of communication technologies.

Unlike the role covered within conventional measuring methodologies, in the proposed architecture the ground control station is expected to face with a mission and platform management task besides the activities of data processing and storage. Fig. 4 shows the double interaction in receiving and transmitting modes between GCS and IAMS units.

\section{Insert Fig. 4}

The GCS subdivides its operations between a receiving channel, managing the information data flow from the aerial platform and the airborne systems, and a transmitting channel, sending the control data flow from ground to air. Both channels can be represented by a layer structure and their related interconnections. Through the receiving channel the raw measurement data are elaborated to obtain measured distances to be stored in a dedicated database. According to applications, a real-time data processing could support the user, rebuilding the object's shape/geometry in a virtual environment and giving important information for mission management. The analysis of telemetry data and their screening to apply flight control strategies is a peculiarity strictly related to the UAV-based architecture, as well as the transmitting operating mode of the GCS. As a matter of fact, the ground station is no longer just a passive collector of data from the measuring probe. It interacts with the sensor-carrying platform to control its motion and to possibly re-plan the mission profile. The GCS design process should approach different complexity stages according to the target level of system automation:

a. remote piloting, based on a direct flight and mission management by means of the ground operator, reduces measurement time with respect to system based on hand-held probes but leaves human resource allocation unchanged;

b. remote monitoring is a sort of semi-autonomous flight mode, demanding to the autopilot system the guidance and control tasks and assigning to the operator just the check of mission accomplishment, the possible mission re-planning and the emergency management; it reduces human efforts besides measurement time;

c. autonomous flight mode demands to the flight control system full authority on mission planning, guidance laws and platform control, also in emergency situations; it requires 
an artificial intelligence to manage the overall system within an unpredictable scenario.

Although airborne flight control systems are generally implemented for unmanned aerial vehicle automation, demanding to ground-based hardware the guidance, control and reconfiguration issues could represent a possible solution to the need for reducing the onboard avionic equipment and maximizing the payload weight fraction.

\section{The design process}

The design process, outlined in Fig. 5, provides a two-level approach: the analytical approach is applied to evaluate the available start-up technology and its limitations and to perform a sensitivity analysis to the design parameters; the experimental approach is applied to test the effectiveness of the proposed design solutions.

An actual implementation of the proposed architecture is herein discussed, focusing on system feasibility and outlining some preliminary results.

According to the main design requirements (Section 5), the need for stationary positioning and the sizing constraints were the primary features to which the analysis and research activity was addressed. Rotary wing platforms and lighter-than-air aircraft were evaluated within the testbed design/definition phase. As the sizing features are strongly related to the mission profile and the indoor application, micro and mini aerial vehicles, with maximum dimension smaller than 1.5 meters, have been evaluated for this application.

\section{Insert Fig. 5}

Platform selection has been carried out comparing configuration layout, maximum dimensions, weight features, flight duration and range, and stabilization devices, where available.

Due to its higher payload to size ratio and despite its sharper dynamic response, a rotary wing configuration better fits for the measurement task than a lighter-than-air configuration. A four-rotor layout was chosen instead of a conventional helicopter-like configuration as flight control, demanded to engines differential rotation, is easier. Moreover, platform behaviour is expected to have a smoother response to control commands and to be less subject to structural vibrations. The Silverlit RC X-UFO (Fig. 6) was selected as sensor carrying platform for a preliminary system testing phase. It is a small, lightweight, structurally robust and crash-proof vehicle, provided with the basic features for performing as indoor flight testbed. The RC XUFO is powered by four individual geared electric motors, constantly monitored by a 


\section{Insert Fig. 7}

Table II reports some results of the first phase of the exploratory experimental activity, aimed to preliminarily evaluate performance features of the bare aerial platform and to assess efficient energy source solutions.

\section{Insert Table II}

Comparing the first and the third flight test allows to evaluate the efficiency of the Lithium Polymer (Li-Po) technology in meeting the project requirements in terms of maximum weight and mission duration. As a matter of fact, Li-Po battery technology is characterized by an 
increased flight time, a significantly decreased weight compared to Nickel Metal Hydride (NiMH) or Nickel Cadmium (NiCd) packs, a smaller physical size to easily fit in the aerial platform, and the ability to supply current at high rates.

The second flight test was carried out by increasing the dead weight fraction, in order to evaluate the maximum payload weight of the selected configuration. This limitation, concerning the four-rotor configuration, is strictly related to the propulsive system and could be partially removed by improving engine performance. On the other hand, similar platforms characterized by higher payload weight fraction are available, granting up to 400 grams to be carried onboard (Draganfly).

The actual implementation of the proposed system has been further developed by integrating an infrared (IR) optical-based technology for tracking the platform in the indoor working environment. Experimental testing has been devoted to design the integrated system and to quantitatively evaluate the overall system performance in carrying out a measurement task. Tracking performance have been analyzed in terms of capabilities to provide position and attitude data for platform control and navigation.

Basically, optical outside-in tracking systems estimate the pose of 3D points (targets) from their projections in different views. A low-cost solution has been realized by using retroreflective spheres as passive targets, Wiimote IR cameras (Lee, 2008), and LED arrays (see Fig. 8).

\section{Insert Fig. 8}

The optical system is based on a set of IR cameras, having an interpolated resolution of $1024 \times 768$ pixels, sampled at a maximum frequency of $100 \mathrm{~Hz}$ and characterized by a viewing angle of approximately $50^{\circ}$. Each camera was coupled with a near-IR strobelight, consisting of a 96-chip LED array with a peak wavelength of $940 \mathrm{~nm}$ and an irradiation angle of approximately $80^{\circ}$. A physical volume of approximately $600 \times 500 \times 300 \mathrm{~cm}$ was equipped with four IR cameras and related strobelights. Passive targets have been made by wrapping around polystyrene spheres a retro-reflective silver transfer film. The target dimensions depend on hardware capabilities and working volume. Fig. 9 provides a virtual reconstruction of the working layout, highlighting the viewing cones of each camera. It is noteworthy that the working volume is consistently reduced with respect to the physical one: it consists of the volume of intersection of at least two cones or four cones for tracking position of a single marker or position and attitudes of three markers, respectively. The platform was equipped with three passive targets, directly mounted on the foam structure, to be tracked during the 
remote flight session. The additional weight due to one airborne target having a diameter of $40 \mathrm{~mm}$ is 2 grams only.

\section{Insert Fig. 9}

The tracking system was able to provide real-time platform positioning and attitudes and to proceed to a virtual reconstruction of the flight (see Fig. 9). A self-localization procedure (Svoboda et al., 2005), requiring only a single marker to be moved throughout the working volume, has been implemented. This method provides intrinsic camera parameters (lens distortion, focal length, ...) as well as camera spatial coordinates and orientations in a roombased reference system. Two experimental tests have been carried out to evaluate tracking system characteristics:

i. accuracy testing: it is aimed at estimating the maximum tracking error within the working volume;

ii. jitter testing: it is aimed at evaluating the scatter in tracking a reference point in static conditions.

On the other hand, the effects of aerial system dynamics on tracking performance have been evaluated in terms of:

a. structural vibrations effects;

b. hovering capabilities;

Accuracy testing has been carried out by measuring a reference known distance, intended as the distance between two markers attached to a calibrated square, several times at different positions within the working volume. These tests allowed to roughly estimate a maximum tracking error of the order of $10 \mathrm{~mm}$.

The static jitter has been evaluated by tracking in static conditions a reflective marker positioned on the aerial platform. As shown by the scatter plot of marker's coordinates with the aerial platform at ground (Fig. 10), the jitter during a 2-s static test is less than $2 \mathrm{~mm}$ for all the coordinates. Literature studies demonstrate that this order of magnitude is strictly related to the tracking technology and could be consistently reduced (until submillimiter accuracy) (Pintaric and Kaufmann, 2007, How et al., 2008).

Structural vibrations characterizing aerial system dynamics during operation are mainly induced by turning rotors. As the proposed implementation involves airborne markers, they represent a key issue for system feasibility. Although ground proximity affects platform dynamics, vibration effects have been evaluated by measuring aerial system positioning at 
ground with rotors turning. However in-flight analysis strongly depends on capabilities to perform stationary point flight, referring either to the human operator or to the flight control system. Fig. 10 shows a scatter plot of 3D vehicle coordinates at ground with rotors turning at their minimum rpm speed (about $40 \%$ of maximum speed). A maximum tracking error of approximately $\pm 4 \mathrm{~mm}$ for the $z$ coordinate can be observed when rotors are turned on. Higher tracking errors can be noted referring to the $x$ and $y$ coordinates, whose orders of magnitude are $10 \mathrm{~mm}$ and $30 \mathrm{~mm}$ for a $4-\mathrm{s}$ test, respectively. The increasing trend in $y$ coordinate may be related to a coupling between throttle command and yaw response, mainly due to the effects of slight differences in engine rotations, uncompensated by the mechanical gyro.

\section{Insert Fig. 10}

As to the aerial platform performance, a 2-s hovering has been used as reference maneuver to estimate capabilities of stationary point flight. Since mission control through PC have clearly shown the inadequacy of embedded mechanical gyro functioning and the consequent need for a feedback loop to further stabilize the platform, the hovering flight for the preliminary testing phase has been realized by a human operator. As a matter of fact, such remote piloting mode perform a loop closure by using the human control as a compensator. It is noteworthy that the obtained flight performance are strongly related to the compensator model and, in this case, to the human skills. Nevertheless, these tests were needed to assess the tracking system and, hence, capability to gather information for a conventional, algorithm-based feedback control. The aerial platform demonstrated to be able to hold a fixed position, remaining inside a $10 \times 10-\mathrm{cm}$ box during the $2-\mathrm{s}$ commanded maneuver, with a variation in altitude of approximately $\pm 2 \mathrm{~cm}$. It is noteworthy that these performance are strictly related to the aerial platform characteristics, in terms of self-stabilization during flight, and to the loop closure, whose model is unknown and highly depending on human operator skills. In order to remove this source of variability and to improve system performance, the design of a control system, aimed at stabilizing the aerial platform and enhancing position holding capabilities, is needed. A preliminary design phase is under development. A classical PID technique has been firstly investigated. The controller structure consists of different independent loops for $x-y$ position holding (through pitch and roll angles feedback, respectively), altitude holding and yaw control. As an example, Fig. 11 reports the structure of the altitude hold loop.

\section{Insert Fig. 11}

The feedback loop can be expressed in the following general form: 


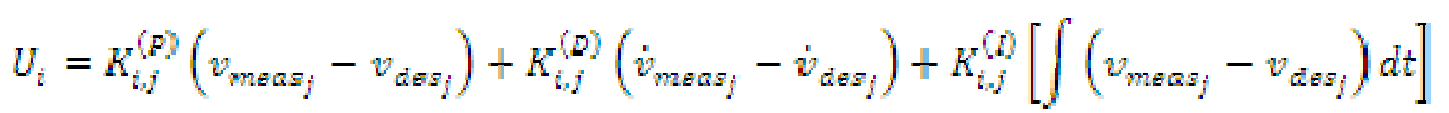

where the $U_{i}(\mathrm{i}=1, \ldots, \mathrm{m})$ indicates the $i$-th control variable within a set of $m$ control commands, $v_{j}(j=1, \ldots, n)$ is the $j$-th feedback state variable within a set of $n$ states, the subscripts meas and des represent measured and desired values, respectively. The terms $K_{i, j}^{(P)}$, $K_{i, j}^{(D)}$, and $K_{i, j}^{(D)}$ are the proportional, derivative, and integral components of the feedback controller involving the $i$-th control variable and the $j$-th state variable. As to the present application, the state vector $V \in \mathbb{R}^{6}$ includes roll angle $(\phi)$, pitch angle $(\theta)$, yaw angle $(\psi)$, and the position coordinates $(x, y, z)$, whereas the control vector $U \in \mathbb{R}^{4}$ consists of the control commands, i.e. throttle $\left(U_{1}\right)$, pitch command $\left(U_{2}\right)$, roll command $\left(U_{3}\right)$ and yaw command $\left(U_{4}\right)$.

As the real platform dynamics can be hardly represented through an analytical model, these preliminary experimental activities are critically important for control system design. As a matter of fact, flight tests provide fundamental data sets for experimentally identify a dynamic model of the aerial platform. According to this model, the gain synthesis phase should be carried out for determining suitable values of the PID control parameters for all the feedback loops. It has to be noted that, as to the present implementation, a multi-dimensional array consisting of three $\mathbb{R}^{4 * 6}$ matrices has to be obtained.

Further investigations have been carried out to evaluate the matching of the proposed architecture with existing LMS instruments. The feasibility analysis has been focused on two reference LMS solutions, both referring to contact-based instruments, supporting the implementation of portable probing devices, and based on distributed wireless sensor networks. The indoor GPS (i-GPS) is a modular tracking system based on laser and infrared lights (Metris), while the Mobile Spatial coordinate Measuring System (MScMS) is an ultrasound-based measurement system (Franceschini et al., 2008, Franceschini et al., 2009, Maisano et al., 2009). As a matter of fact, CAD-based feasibility analysis (Fig. 12) highlights the opportunities for a four-rotor configuration to house the receiving devices, whereas platforms providing capabilities to move in an indoor environment an extra payload are available (Draganfly). Nevertheless, further modifications to the actual measuring hardware should be made in order to eliminate the useless "packaging" weight, to reduce the energy source weight by fitting energy specifics to the overall system performance, and to provide proper housing to the measuring probe. Although fulfilling requirements of mission duration could be granted by available technology in terms of energy sourcing (i.e. Li-Po battery 
capacity-to-weight ratio), a re-organization of LSM procedure should be planned, considering a repartition of the working volumes and applying a time-saving strategy, based on concurrent measurement sessions and multiple unmanned vehicles integration.

\section{Insert Fig. 12}

\section{Innovative strategies for LSM system management}

The proposed architecture could provide further advantages by implementing innovative strategies of system management, based on team of agents, coordinated and cooperative control, employment of hybrid teams.

The need for monitoring and remotely sensing large areas reducing human intervention boosted the development of the multi-AUVs concept. The integration of multiple platforms, searching large areas for gathering data and sending them to a remote host station, is the subject of several research activities, primarily involving the control system community (Giulietti et al., 2000, Beard et al., 2001, Inalhan et al., 2002). As a matter of fact, formation control is a real challenge for control designers, being responsible of system effectiveness and related economic competitiveness.

Since a swarm of vehicles is demonstrated to be more efficient than a single platform, whenever large areas and remote locations have to be monitored, an innovative distributed approach to large scale metrology could be based on integration of multiple aerial platforms sharing the measuring task. This strategy, that requires a repartition of the working volume, gets its strength from two factors:

1. strong time reduction due to the parallelization of the activities;

2. improvement of communication ranges by implementing a multi-hop approach to send information to the ground station.

Within the proposed system management strategy, more levels of automation can be involved in this design. First level of automation is related to the capability of aerial platform(s) and related systems to follow pre-programmed trajectories, characterizing the mission profile, and to autonomously perform flight stabilization and control. This task is demanded to a common autopilot system, consisting of inertial measurement unit, pressure transducers for flight speed and barometric altitude measurements, and onboard processor. Therefore, the operating scenario should take into account pre-flight mission planning, mainly consisting in the 
definition of measurement sequences. For aerial swarms application, the planning operation follows a repartition of working volumes and the assignment of covering strategies.

Further improvement of system effectiveness could be achieved by coordinated formation control (How et al., 2004, Casbeer et al., 2005, Finke et al., 2006), intended as capability to dynamically change the mission profile according to events occurred during the flight. Changes to the pre-programmed trajectory could be due to information gathered during measurements, failure of team components, loss of communication links, obstacle avoidance, and every modification of task priority list. Management of the formation can be centralized or decentralized. The former case is based on a formation manager, either airborne or groundbased, playing the role of reference agent and responsible for the swarm network topology. On the other hand, within the decentralized scheme, each member of the formation has a certain level of decision capability, although a global decision-making and reconfiguration algorithm characterize the formation as a single entity. Coordinated control represents a challenging feature of networked systems, requiring design efforts to be focused on innovative control techniques and reliable automation technologies, in a way that multiple vehicles could be managed by a single ground operator, if adequately supported. According to the selected scheme, human role is, then, delegated to mission managing and/or system monitoring.

Another interesting strategy related to formation control, addressed to a further strengthening of system automation, is based on assigning global tasks to the fleet, instead of distinct tasks to each member. According to this approach, commonly named cooperative control, the swarm should be provided of an internal intelligence in order to determine by itself the best way to accomplish the mission tasks and to select the optimal displacement of the mobile agents. A comprehensive analysis of the available literature shows that the main challenges of this control strategy are mathematical model complexity and the communications coordination, affecting real-time implementation issues.

Variety of operating environments for large scale dimensional measurement (aerospace, shipbuilding, railway, ...) could take advantages of implementing hybrid teams based on (semi)autonomous agents. This approach could maximize system effectiveness whenever, it is possible to subdivide the working volume in different environmental contexts. Manufacturing and assembly within aerospace applications could represent an interesting case study for testing a hybrid architecture, based on carrying the measuring technology by means of ground vehicles and aerial platforms, integrated within the same network. 


\section{Conclusions}

According to the growing interest and the wide application of large scale metrology, a novel architecture has been proposed with reference to distributed systems and contact-based technologies. Through an investigation of existing solutions in the LSM field and their related drawbacks, a UAV-based system has been analyzed as an alternative to conventional human or robot based systems. Features concerning architecture modularization and operational rules have been compared, highlighting substantial similarities in the basic elements of the architecture and, on the contrary, an essential reinterpretation of the monitoring station role. A practical implementation of the proposed solution has been developed, demonstrating system feasibility as to indoor tracking, capabilities to be fully controlled through a ground station and to carry on board hardware equipment for measurement. On the other hand, experimental testing stressed the importance of platform flight performance and of an active feedback loop for providing a stable stationary flight and an accurate positioning. Further research work will be carried out on flight control system design and on hardware equipment, selecting, integrating and testing different technologies for Large Scale Metrology applications.

\section{References}

Anderson, P. T., Beauregard, G. L., Cherry, C. D., (2006), "Magnetic tracking system", United States Patent, Patent number: 7096148

ANSI/ASME B89.4.19-2006 (2006), "Performance Evaluation of Laser-Based Spherical Coordinate Measurement Systems"

Beard, R. W., Lawton, J., Hadaegh, Y. (2001), “A Coordination Architecture for Spacecraft Formation Control", IEEE Transactions on Control Systems Technologies, Vol. 9, No. 6, pp. 777-790

Casbeer, D. W., Kingston, D. B., Beard, R. W., McLain, T. W., Li, S., Mehra, R. (2006), "Cooperative Forest Fire Surveillance Using a Team of Small Unmanned Aerial Vehicles", International Journal of Systems Science, Vol. 37, No. 6, pp. 351-360

Chen, J.H., Lee, S.C., DeBra, D., (1994), “Gyroscope Free Strapdown Inertial Measurement Unit by Six Linear Accelerometers”, Journal of Guidance, Control, and Dynamics, Vol. 17, No. 2, pp. 286-290 
Cuypers, W., Van Gestel, N., Voet, A., Kruth, J.-P., Mingneau, J., Bleys, P. (2008), “Optical Measurement Techniques for Mobile and Large-Scale Dimensional Metrology", Optics and Lasers in Engineering, doi: 10.1016/j.optlaseng.2008.03.013

Draganfly Innovations Inc web site: http://www.draganfly.com/

Estler W.T., Edmundson K. L., Peggs G. N. and Parker D. H. (2002), "Large-Scale Metrology - An Update”, CIRP Annals - Manufacturing Technology, Vol. 51, No. 2, pp. 587-609

Finke, J., Passino, K. M., Sparks, A. G. (2006), “Stable Task Load Balancing Strategies for Cooperative Control of Networked Autonomous Air Vehicles", IEEE Transactions on Control Systems Technology, Vol. 14, No. 5, pp. 789-803

Franceschini, F., Galetto, M., Maisano, D., Mastrogiacomo L., (2008), "Mobile Spatial coordinate Measuring System (MScMS) - Introduction to the system”, to appear in International Journal of Production Research, DOI: 10.1080/00207540701881852

Franceschini, M., Maisano, D., Mastrogiacomo L., Pralio, B., (2009), "Ultrasound Transducers for Large Scale Metrology: A Performance Analysis for Their Use by the MScMS”, to appear in IEEE Transactions on Instrumentation and Measurement

Giulietti, F., Pollini, L., Innocenti, M. (2000), “Autonomous Formation Flight”, IEEE Control Systems Magazine, Vol. 20, No. 6, pp. 34-44

How, J. P., King, E., Kuwata, Y. (2004), "Flight Demonstrations of Cooperative Control for UAV Teams", Proceedings AIAA 3rd Unmanned Unlimited Technical Conference, Workshop and Exhibit, Chicago, IL

How, J. P., Bethke, B., Frank, A., Dale, D., Vian. J. (2008), "Real-Time Indoor Autonomous Vehicle Test Environment”, IEEE Control Systems Magazine, Vol. 28, No. 2, pp. 51-64

Inalhan G., Stipanovic, D. M., Tomlin, C. J. (2002), "Decentralized Optimization with Application to Multiple Aircraft Coordination", Proceedings IEEE International Conference on Decision and Control, Las Vegas, NV

Kindratenko, V. (1999), "Calibration of Electromagnetic Tracking Devices”, Virtual Reality: Research, Development, and Applications, Vol. 4, pp. 139-150

Lee, J. C. (2008), “Hacking the Nintendo Wii Remote,” IEEE Pervasive Computing, Vol. 7, No. 3, pp. 39-45 
Maisano, D., Jamshidi, J., Franceschini, F., Maropoulos, P., Mastrogiacomo, L., Mileham, A., Owen, G. (2009), “Comparison of Two Distributed Large Volume Measurement Systems: MScMS and iGPS", to appear in Proceedings of the Institution of Mechanical Engineers, Part B, Journal of Engineering Manufacture

Metris Company web site: http://www.metris.com/large_volume_tracking_positioning/igps

Newman, J., Schall, G., Barakonyi, I., Schürzinger, A., Schmalstieg, D. (2006), "Wide Area Tracking Tools for Augmented Reality”, Advances in Pervasive Computing, Vol. 207, Austrian Computer Society

Niculescu, D., and Nath, B. (2003), "Ad hoc positioning system (APS) using AOA", Proceedings of IEEE Annual Joint Conference IEEE Computer and Communications Societies (INFOCOM'03), pp. 1734-1743

Ohara, T. (2001), "Scanning probe position encoder (SPPE): A new approach for highprecision and high-speed position measurement system", Proceedings of SPIE, vol. 4344, pp. 552-561.

Pintaric, T., Kaufmann, H. (2007) “Affordable Infrared-Optical Pose Tracking for Virtual and Augmented Reality," Proceedings of IEEE VR Workshop on Trends and Issues in Tracking for Virtual Environments, Springer Verlag, pp. 44-51

Priyantha, N. B., Chakraborty, A., Balakrishnan, H. (2000) “The Cricket Location-Support system", Proceedings of 6th ACM MOBICOM, Boston, MA

Puttock, M. J. (1978), “Large-Scale Metrology”, Ann. CIRP, Vol. 21, No. 1, pp. 351-356

Schoenwald, D. A. (2000), “AUVs: In Space, Air, Water, and on the Ground”, IEEE Control Systems Magazine, Vol. 20, No. 6, pp. 15-18

Svoboda, T., Martinec, D., Pajdla, T. (2005), “A convenient multi-camera self-calibration for virtual environments," Presence: Teleoperators Virtual Environments, vol. 14, no. 4, pp.407-422

Welch, G., Bishop, G., Vicci, L., Brumback, S., Keller, K. (2001), "High-Performance WideArea Optical Tracking The HiBall Tracking System”, Presence: Teleoperators And Virtual Environments, Vol. 10, No. 1, pp. 1-21

Wilson, J. R. (2002), “UAVs and the Human Factor”, Aerospace America, July 2002 
Wood, R. M. (2002), "A Discussion of Aerodynamic Control Effectors (ACEs) for Unmanned Air Vehicles (UAVs)", Proceedings of $1^{\text {st }}$ Unmanned Aerospace Vehicles, Systems, Technologies and Operations Conference, USA 


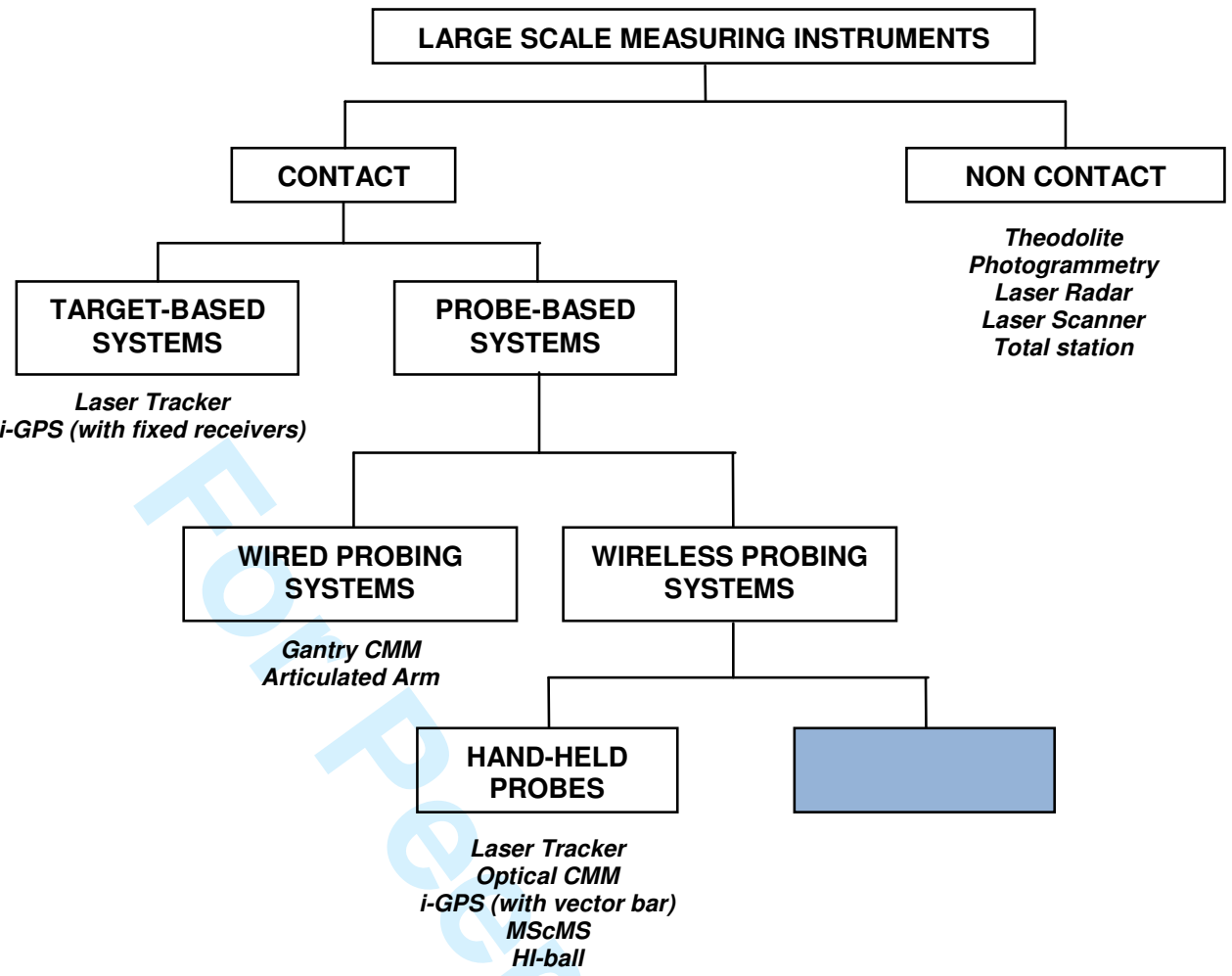

Fig. 1 - Taxonomy for a Large Scale Metrology instruments classification.

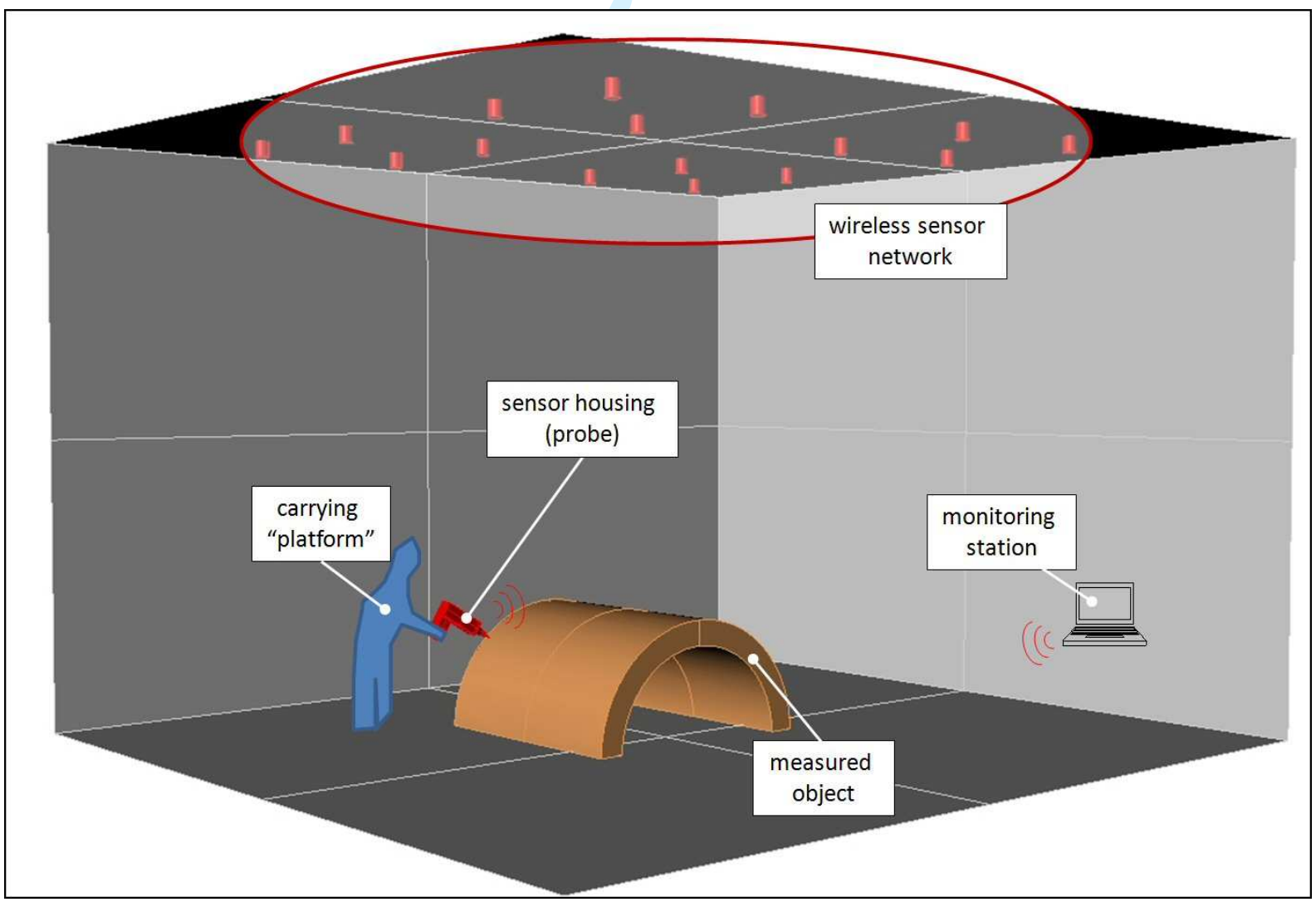

Fig. 2 - Basic elements of system architecture referring to existing probe-based distributed solutions. The wireless sensor network for distributed systems, as well as the single stand-alone unit for centralized systems, shared with the remote sensor set the communication task. 


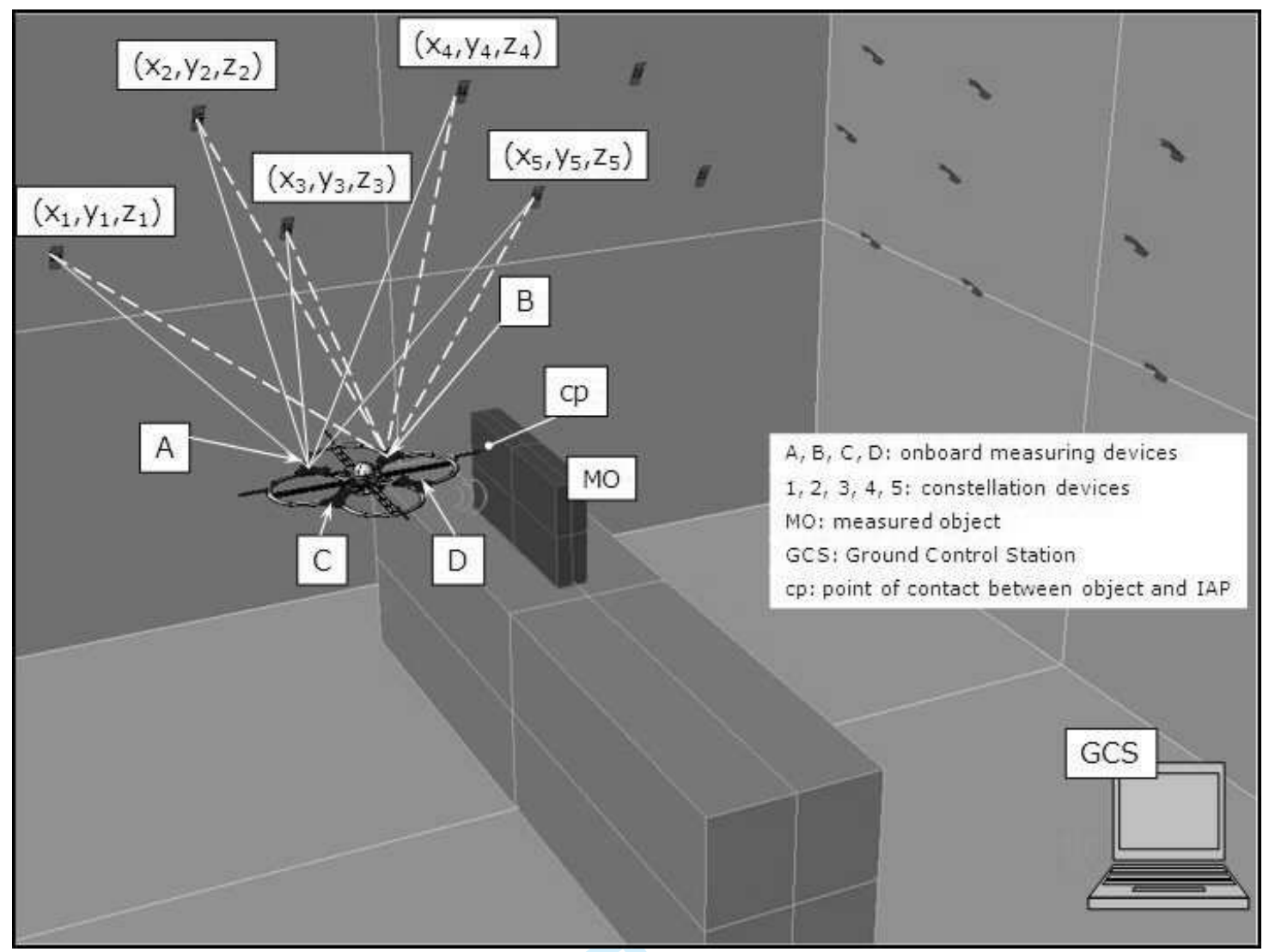

Fig. 3 - Proposed architecture of the UAV-based measuring system and related operating scenario. For a better representation, light grey color is used to indicate IAMS module while dark grey color is used for IAP module. Each constellation device is identified by a set of Cartesian coordinates $\left(\mathbf{x}_{\mathbf{i}}, \mathbf{y}_{\mathrm{i}}, \mathbf{z}_{\mathrm{i}}\right)$. Distances between constellation devices and onboard devices (indicated by solid and dashed lines) are used to compute the spatial coordinates of the point of contact.

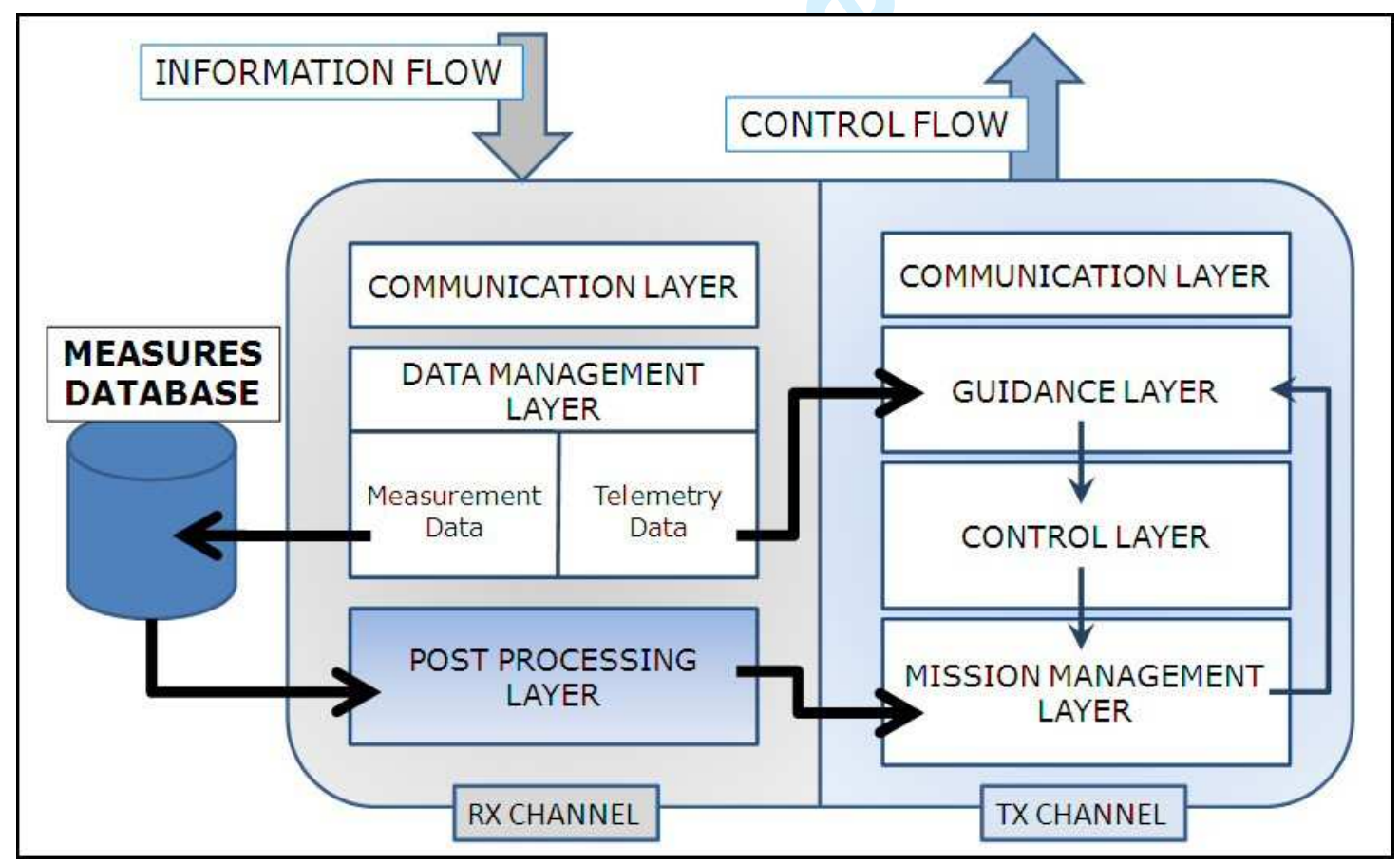

Fig. 4 - Data flow involving Ground Control Station operating modes. 


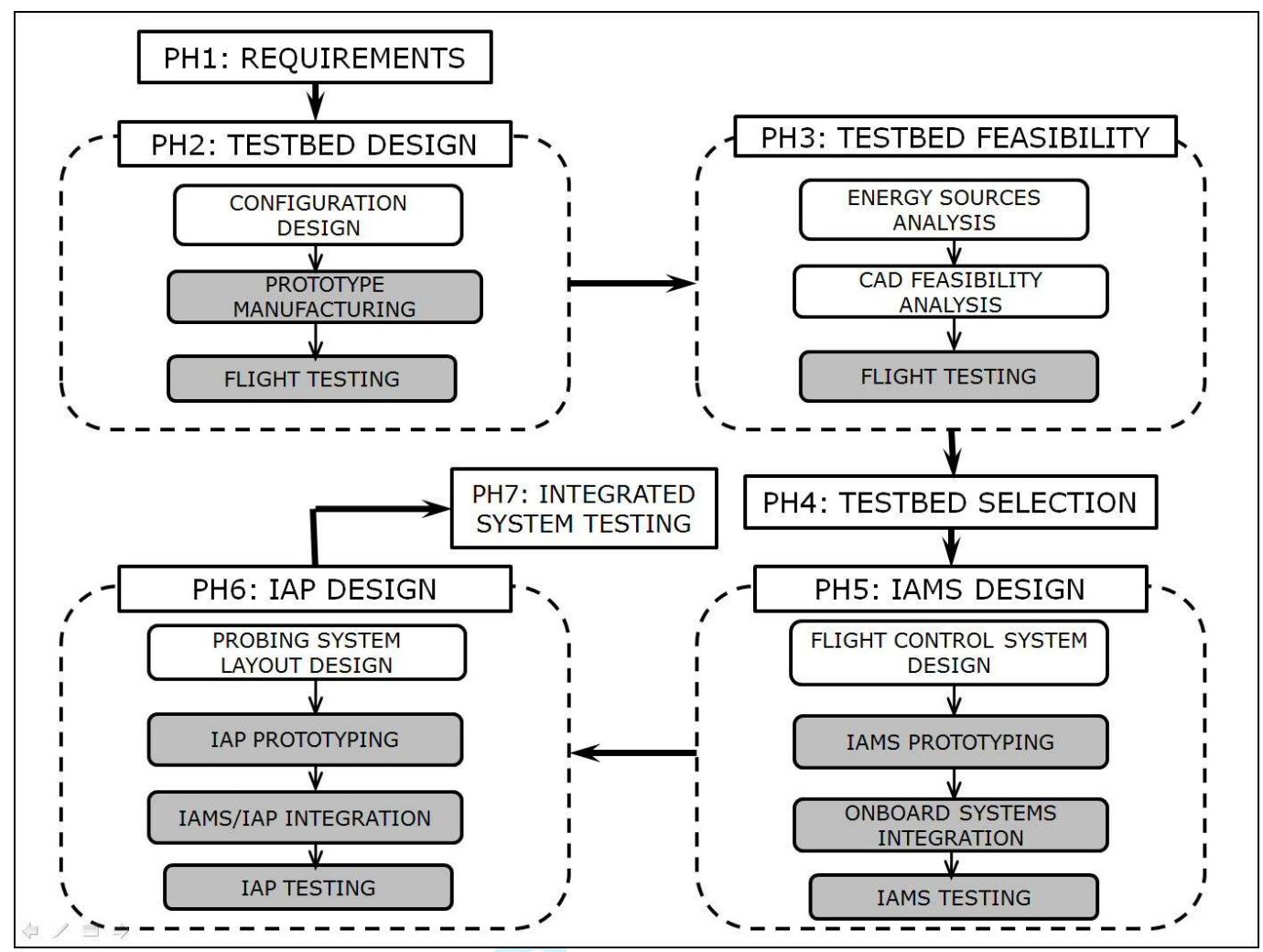

Fig. 5 -Design process outline, highlighting a phase-articulated structure and strong interconnections between analytical and experimental activities (in white and grey boxes, respectively).

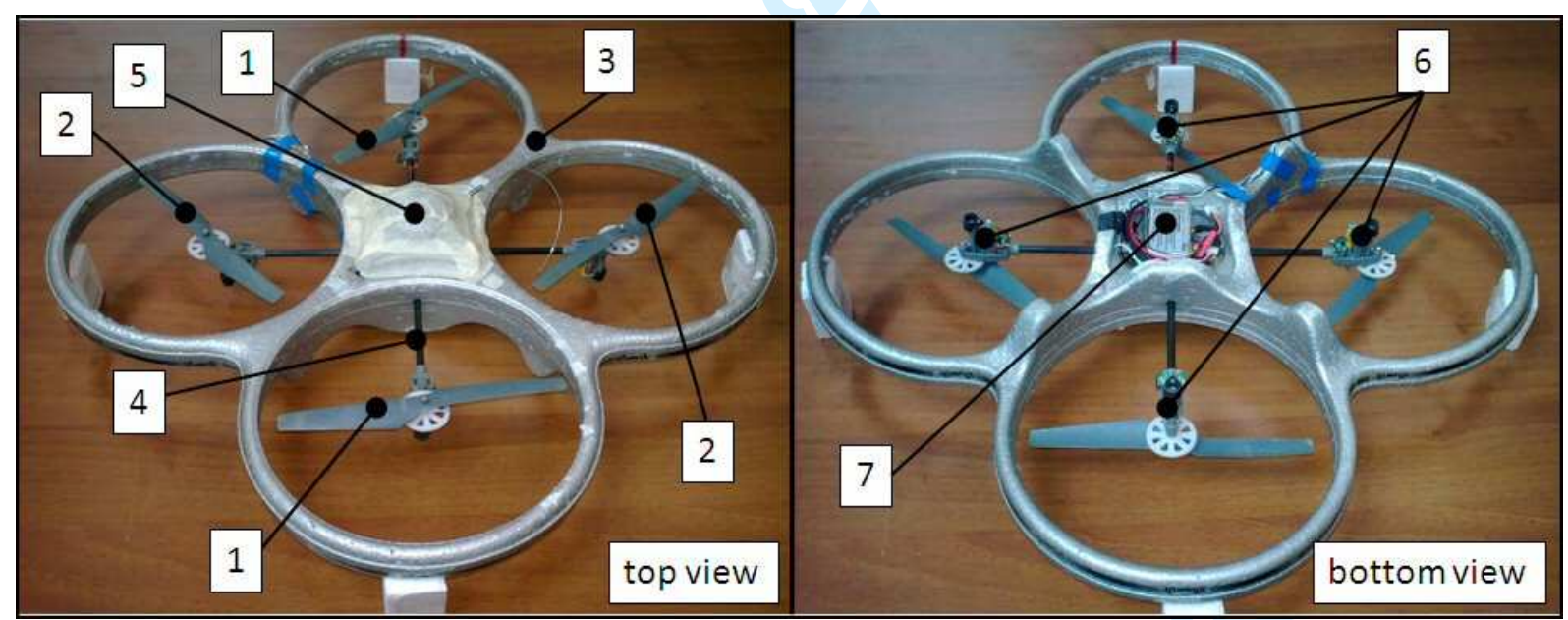

Fig. 6 - The Silverlit RC X-UFO platform during preliminary flight testing activities in the facilities of the Industrial Metrology and Quality Engineering Lab. (Production Systems Dept.) at Politecnico di Torino. Main onboard systems and configuration elements are highlighted (1: clockwise propeller; 2: counter-clockwise propeller; 3: EPP foam-made body; 4: carbon fiber frame; 5: gyro and main control board; 6: geared electric motor; 7: battery case). 


\section{Ground Control Station}

Fig. 7 - Communication links and data exchange between the ground control station and the remote aerial platform, characterizing the preliminary experimental flight testing hardware. Dashed lines indicate hardware and related communication links for future implementation of a telemetry system. Connecting the remote platform to the $\mathrm{PC}$ is aimed to perform feedback control for better platform stabilization.

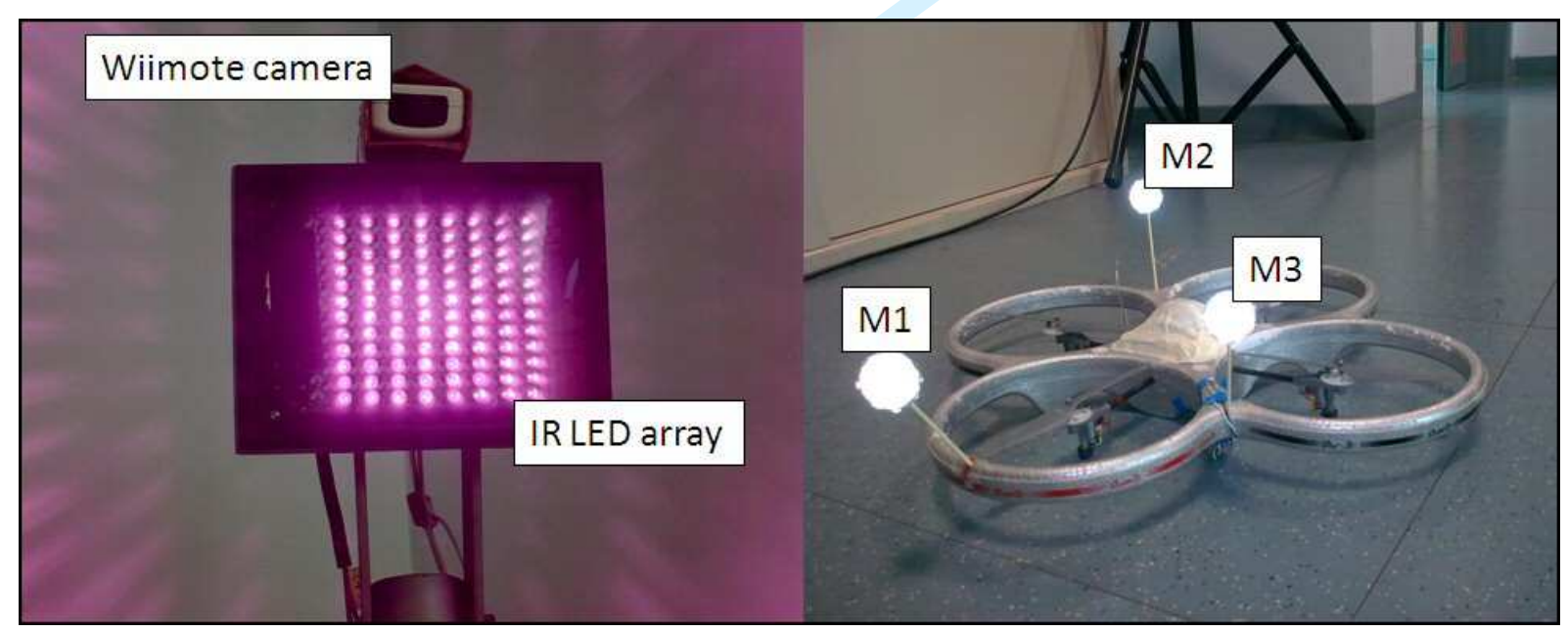

Fig. 8 - IR tracking system setup: IR camera and LED arrays (left picture), and passive markers (M1, M2, M3) mounted on the aerial platform (right picture). 


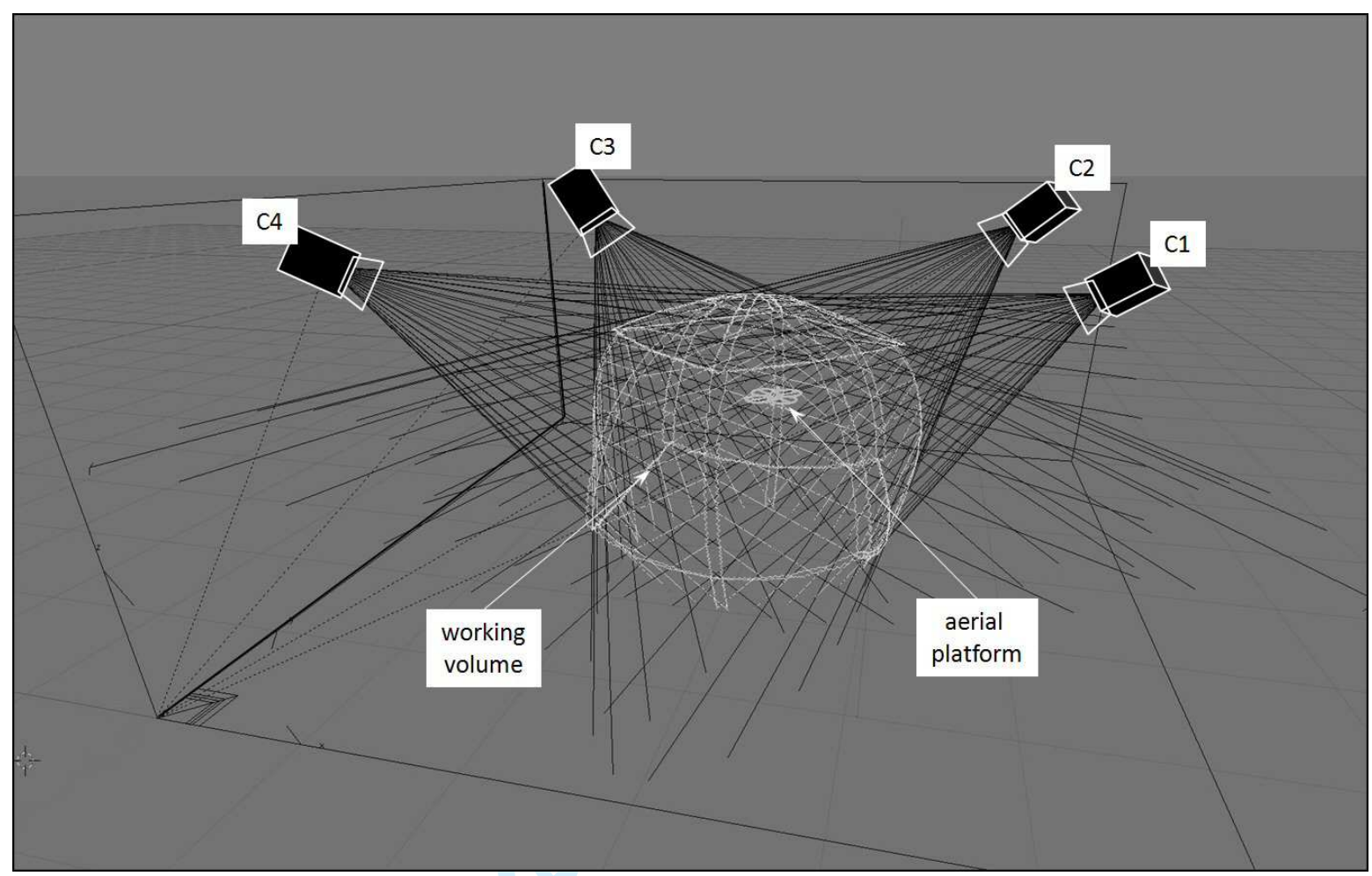

Fig. 9 - Virtual reconstruction of working layout and real-time flight trajectory. The black wireframe represents the viewing cones of the IR cameras (named $\mathrm{C1}, \mathrm{C2}, \mathrm{C3}$, and $\mathrm{C4}$ ), whereas the light grey wireframe represents the working volume, i.e. the volume of intersection of all the four cones.
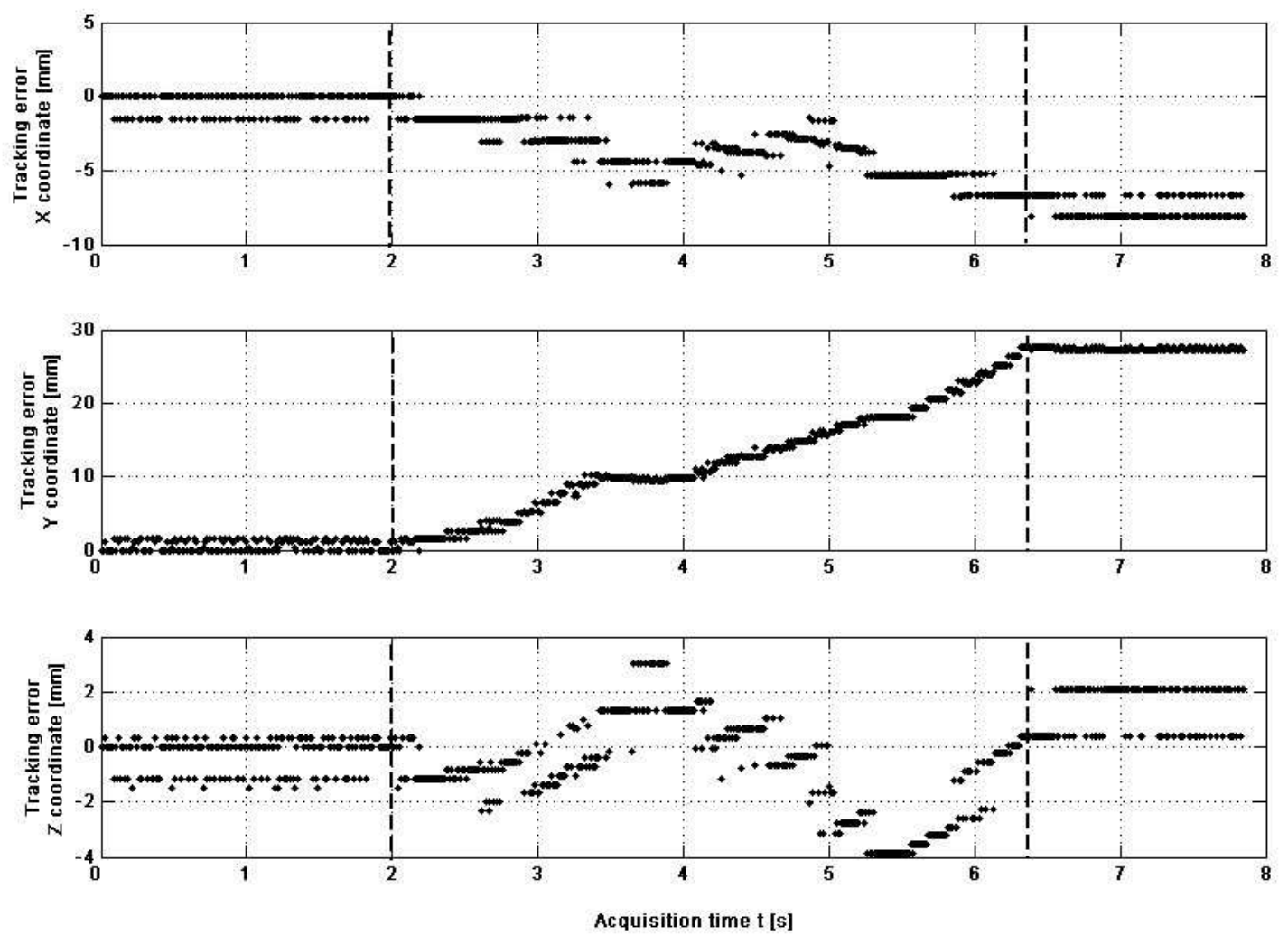

Fig. 10 - Scatter plot of 3D coordinates of an airborne marker. Dashed lines highlight the data acquired with turning rotors $(2 s<\mathrm{t}<6.3 s)$. 

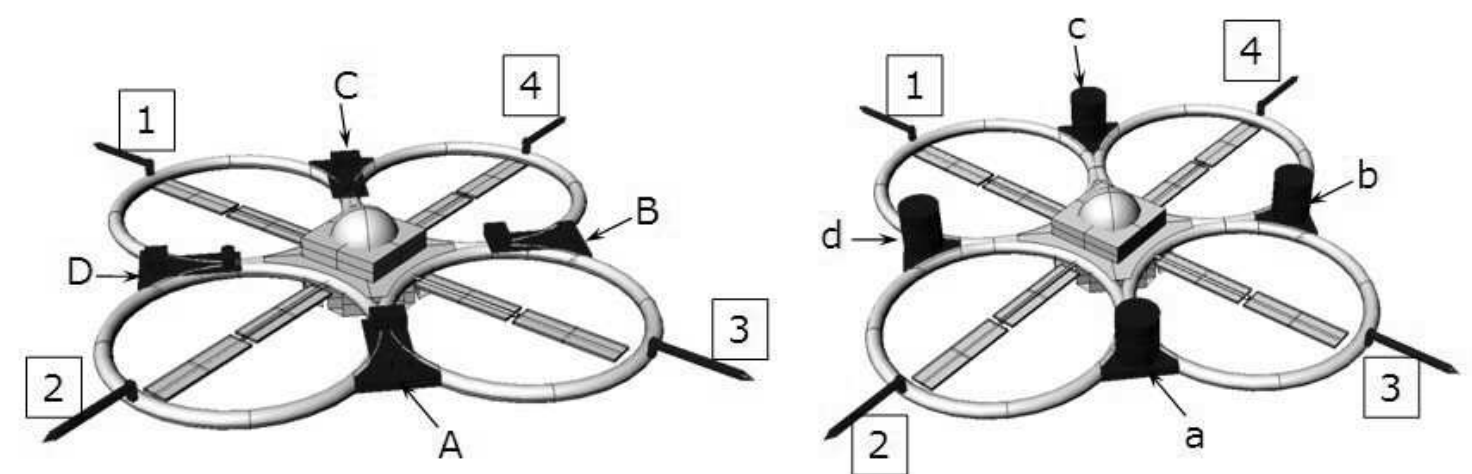

1, 2, 3, 4: contact probes

A, B, C, D: Cricket devices

a, b, c, d: i-GPS RX modules

Fig. 12 - CAD-based feasibility analysis related to the airborne installation of metrological hardware for large volume measurements: the US-based solution referring to MScMS (left picture) and the laser/IRbased solution referring to iGPS (right picture). The light grey color and the dark grey color are used to indicate IAMS and IAP modules, respectively. 


\begin{tabular}{lcc}
\hline Design requirement & & \\
\hline Maximum dimension & {$[\mathrm{m}]$} & $<1.5$ \\
Payload weight & {$[\mathrm{g}]$} & $>400$ \\
Flight duration & {$[\mathrm{min}]$} & $>30$ \\
Mission range & {$[\mathrm{m}]$} & $>50$ \\
Flight stabilization & - & YES \\
Autopilot & - & YES \\
\hline
\end{tabular}

Table I: Preliminary quantification of main design requirements, playing a key role within platform feasibility analysis.

\begin{tabular}{|l|c|c|c|c|}
\hline & & $\mathbf{1}^{\text {st }}$ flight test & $\mathbf{2}^{\text {nd }}$ flight test & $\mathbf{3}^{\text {rd }}$ flight test \\
\hline Max take-off weight & {$[\mathrm{g}]$} & 310 & 370 & 300 \\
\hline Battery type & {$[-]$} & Ni-MH & Ni-MH & Li-Po \\
\hline Battery pack dimension & {$[\mathrm{mm}]$} & $52 \times 20 \times 30$ & $52 \times 20 \times 30$ & $59 \times 20 \times 34$ \\
\hline Battery pack weight & {$[\mathrm{g}]$} & 84 & 84 & 74 \\
\hline Flight endurance & {$[\mathrm{min}]$} & 4 & 2 & 15 \\
\hline Max payload weight & {$[\mathrm{g}]$} & n.a. & 60 & n.a. \\
\hline
\end{tabular}

Table II: Preliminary flight test results on the RC X-UFO platform. 